\title{
LOS REGÍMENES DE TRANSICIÓN DEL LICENCIAMIENTO AMBIENTAL EN COLOMBIA VISTOS DESDE LA ACTIVIDAD MINERA*
}

\author{
Andrés Gómez Rey** \\ Camilo Alexander Rincón ${ }^{* * * *}$ \\ Gloria Amparo Rodríguez ${ }^{* * * *}$
}

Fecha de recepción: 27 de agosto de 2015

Fecha de evaluación: 7 de diciembre de 2015

Fecha de aprobación: 29 de febrero de 2016

Artículo de reflexión

DOI: http://dx.doi.org/10.18359/prole.1976

Forma de citación: Gómez, A., Rincón, C. \& Rodríguez, G. (2016). Los regímenes de transición del licenciamiento ambiental en Colombia vistos desde la actividad minera.Revista Prolegómenos Derechos y Valores, 19, 38, 161-181. DOI: http://dx.doi.org/10.18359/prole.1976

\section{Resumen}

La licencia ambiental es un instrumento de planificación que permite realizar el análisis previo y establecer las posibles consecuencias o impactos que genera un proyecto, obra o actividad, para tomar las medidas correspondientes, tal y como lo propone el título VIII de la ley 99/1993. El desarrollo normativo de esta figura se da, en especial, desde la expedición de la ley 99/1993 y los diferentes decretos que han reglamentado el procedimiento para su otorgamiento, cuestión sobre la cual versa el presente documento: las transiciones entre cada norma y los requisitos y reglas de cada una vistos desde la actividad minera. Como metodología se propone estudiar desde la dogmática jurídica, las fuentes del derecho, particularmente de la doctrina, la

\footnotetext{
Este artículo es resultado del trabajo de dos de los autores al interior del Ministerio de Ambiente y Desarrollo Sostenible en ejercicio y respuesta al radicado MADS 4120-E1-33037 del 25 de septiembre de 2014; así como del proyecto de investigación titulado "La participación administrativa ambiental en los procedimientos para el otorgamiento de licencias ambientales", que adelanta la línea de investigación en derecho ambiental de la Facultad de Jurisprudencia de la Universidad del Rosario (Bogotá, Colombia), la cual forma parte del Grupo de Investigación en Derecho Público.

** Abogado de la Universidad de La Sabana (Bogotá, Colombia), especialista en Derecho Ambiental y magíster en Derecho Administrativo de la Universidad del Rosario (Bogotá, Colombia). Profesor de cátedra de pregrado y posgrado de diversas instituciones, entre ellas la Universidad de La Salle (Bogotá, Colombia), Universidad Icesi (Cali, Colombia) y Universidad del Rosario. Ha sido asesor de entidades públicas y privadas. Cuenta con diversas publicaciones sobre derecho ambiental y servicios públicos domiciliarios. Correo electrónico: agomezrey@me.com

**** Abogado de la Universidad La Gran Colombia (Bogotá, Colombia), especialista en Derecho Ambiental de la Universidad del Rosario (Bogotá, Colombia), especialista en Derecho Administrativo de la Universidad Nacional de Colombia, (Bogotá, Colombia). Asesor del Ministerio de Ambiente y Desarrollo Sostenible. Profesor de cátedra de posgrado de la Universidad del Rosario. Correo electrónico: crincon@minambiente.gov.co

***** Abogada. Ph.D. en Sociología Jurídica e Instituciones Políticas. Actualmente se desempeña como profesora titular de carrera de la Facultad de Jurisprudencia de la Universidad del Rosario (Bogotá, Colombia), donde además es directora de la especialización y de la línea de investigación en derecho ambiental. Cuenta con diferentes publicaciones sobre temas ambientales y étnicos y ha sido editora académica de otras obras. Correo electrónico: gloria.rodriguez@urosario.edu.co; http://gloriamparodriguez.blogspot.com
} 
jurisprudencia y la ley, con el fin de abstraer los conceptos integrantes del régimen normativo transicional de la licencia ambiental en relación con la actividad minera, usando el método lógico-deductivo con el propósito de establecer consecuencias desconocidas desde principios conocidos. Es decir, se reflexiona sobre el licenciamiento ambiental en materia minera, mostrando algunas opciones interpretativas que se presentan con cada cambio normativo, identificando las principales problemáticas y ofreciendo posibles soluciones.

\title{
Palabras clave:
}

Recursos naturales renovables, licencia ambiental, regímenes de transición, actividad minera, título minero, exploración y explotación de recursos naturales no renovables.

\section{TRANSITION SCHEMES OF THE ENVIRONMENTAL LICENSING IN COLOMBIA SEEN FROM MINING ACTIVITY}

\begin{abstract}
Summary
The environmental license is a planning tool that allows to carry out the previous analysis and to establish the possible consequences or impacts generated by a project, work or activity, to take appropriate measures, as proposed by the title VIII of Act 99/1993. Regulatory development of this figure is given, in particular, from the issue of Act 99/1993 and the various decrees which have regulated the procedure for its granting, question with which this document deals: the transitions between each norm and the requirements and rules of each one seen from the mining activity. As a methodology it is proposed to study, from the legal dogmatic, the sources of law, particularly of the doctrine, jurisprudence and legislation, in order to abstract the concepts of the regulatory transitional regime of environmental license in relation to mining activity, using the logical-deductive method with the purpose of establishing unknown consequences from known principles. That is to say, it reflects on the environmental licensing in the mining field, showing some interpretative options that are presented with each regulatory change, identifying the main problems and offering possible solutions.
\end{abstract}

\section{Keywords:}

Renewable natural resources, environmental license, transition schemes, mining activity, mining title, exploration and exploitation of non-renewable natural resources.

\section{OS REGIMES DE TRANSIÇÃO DO LICENCIAMENTO AMBIENTAL NA COLÔMBIA VISTOS DESDE A ATIVIDADE MINERADORA}

\begin{abstract}
Resumo
A licença ambiental é um instrumento de planejamento que permite realizar a análise prévia e estabelecer as possíveis consequências ou impactos que gera um projeto, obra ou atividade, para tomar as medidas correspondentes, tal e como é proposto no título VIII da Ley 99/1993. O desenvolvimento normativo desta figura ocorre, em especial, desde a expedição da Ley 99/1993 e dos diferentes decretos que regulamentam o procedimento para a sua outorga, questão sobre a qual versa o presente documento: as transições entre cada norma e os requisitos e regras de cada uma vistos desde a atividade mineradora. Como metodologia a proposta é estudar
\end{abstract}


desde a dogmática jurídica, as fontes do direito, particularmente da doutrina, da jurisprudência e da lei, com o fim de abstrair os conceitos integrantes do regime normativo transicional da licença ambiental em relação a atividade mineradora, usando o método lógico-dedutivo com o propósito de estabelecer consequências desconhecidas desde princípios conhecidos. Ou seja, reflexiona-se sobre o licenciamento ambiental em matéria de mineração, mostrando algumas opções interpretativas que são apresentadas com cada mudança normativa, identificando as principais problemáticas e oferecendo possíveis soluções.

\section{Palavras-chave:}

Recursos naturais renováveis, licença ambiental, regimes de transição, atividade mineradora, concessão da exploração das minas, busca e exploração de recursos naturais não renováveis.

\section{Introducción}

La licencia ambiental ${ }^{1}$ se constituyó a partir de la expedición de la ley 99/1993 en el principal instrumento para la evaluación ambiental en Colombia. Para su obtención, la ley y sus reglamentos han indicado de manera taxativa los proyectos, obras o actividades sujetos a dicho instrumento de manejo y control ambiental y el procedimiento que debe adelantarse para su consecución. A lo largo del tiempo dicha normatividad ha presentado variaciones, con cambios de fondo y forma, en especial, en cuanto a los requisitos para su obtención, las actividades que requieran de la misma y su procedimiento (Rodríguez, 2011).

1 El título VIII de la ley 99/1993 consagró en su artículo 49 que la ejecución de obras, el establecimiento de industrias o el desarrollo de cualquier actividad que de acuerdo con la ley y los reglamentos, pueda producir deterioro grave a los recursos naturales renovables o al medioambiente o introducir modificaciones considerables o notorias al paisaje requerirán de una licencia ambiental; entendiendo por ella en su artículo 50 que se trata de la concesión de autoridad ambiental competente para la ejecución de una obra o actividad, sujeta al cumplimiento por el beneficiario de la licencia de los requisitos que la misma establezca en relación con la prevención, mitigación, corrección, compensación y manejo de los efectos ambientales de la obra o actividad autorizada, creando una lista taxativa de actividades que para su ejecución deben obtener la licencia ambiental como instrumento de manejo y control.
Esos cambios no son ajenos a las reglas de la aplicabilidad de la norma en el tiempo consagradas en la ley 153/1887, en donde se establece el modo en el que los preceptos deben hacer tránsito entre una disposición antigua y una nueva que regula integralmente la misma materia. A continuación pretendemos mostrar que los cambios en los regímenes de transición del licenciamiento minero, han terminado por generar incertidumbre jurídica y ante la escasa existencia de doctrina al respecto, estamos en deuda de aportar elementos para promover el debate sobre este tema ${ }^{2}$.

Este texto es resultado del trabajo de dos de los autores para la elaboración de un concepto en el Ministerio de Ambiente y Desarrollo Sostenible (MADS) $(2014)^{3}$, y es producto del proyecto de investigación "La participación administrativa ambiental en los procedimientos para el otorgamiento de licencias ambientales", cuyo objetivo general es realizar una evaluación al ejercicio de los procesos para el otorgamiento de licencias ambientales en Colombia y de esta forma, establecer resultados que señalen los vacíos que se han presentado en su implementación.

2 Es necesario mencionar que se presenta escasa doctrina y que no hay jurisprudencia sobre este tema. Se destacan los aportes de Macías (2006) y Rodríguez (2009, 2011) sobre la cuestión de licencias ambientales.

3 El cual además contó con los aportes, revisión y suscripción de la doctora Constanza Atuesta, entonces jefe de la Oficina Asesora Jurídica del Ministerio a quien agradecemos dicha labor. 
Antes de comenzar es importante tener en cuenta que la Real Academia de la Lengua Española (2016) expresa que por régimen debe entenderse el conjunto de normas que gobiernan o rigen una cosa o una actividad y por transición "la acción y efecto de pasar de un modo de ser o estar a otro distinto"; por lo cual podemos afirmar que un régimen de transición normativo se trata de un articulado específico que permite la adaptación en el tiempo de las condiciones de una regulación anterior a una posterior, permitiendo que mientras esto ocurre, se sostengan como válidas ${ }^{4}$ las primeras para quienes en dicha época hubiesen cumplido los preceptos o requisitos que la ley contenía.

Para lograrlo, estudiaremos los regímenes de transición que en materia de autorizaciones ambientales sobre actividades mineras encontramos en nuestro ordenamiento jurídico, para así establecer los requisitos de cada cambio y elaborar conclusiones. El método utilizado para esta investigación parte de la recopilación y análisis de bibliografía especializada, en la búsqueda de dogmática jurídica para la descripción, conocimiento y mejoramiento del entorno jurídico. Tal y como se indicó en el resumen usando el método lógico-deductivo con el fin de establecer consecuencias desconocidas desde principios conocidos. Se informa al lector desde ya, que no se encuentra en la doctrina ni la jurisprudencia mayor información directamente relacionada con la cuestión planteada.

\section{A. Análisis de las normas que comprenden los regímenes de transición}

Se expondrá aquí la forma como se ha dado en la legislación colombiana el paso entre los regímenes de transición y efectuaremos un análisis sobre su implementación. Desde el punto de vista minero encontramos las normas que aparecen en la gráfica 1 .

Y desde la perspectiva ambiental encontramos especialmente las normas que se muestran en la gráfica 2 .

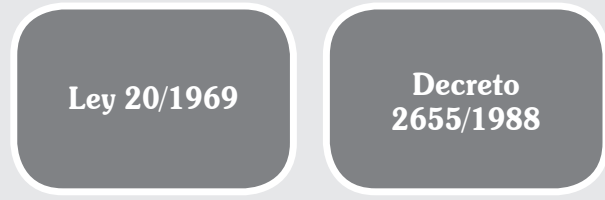

Constitución

Política de

Colombia de 1991

Gráfica 1. La transición desde el derecho minero
Ley 685 del 15 de

agosto de 2001

Fuente: elaboración propia.

4 Generando situaciones jurídicas consolidadas. 


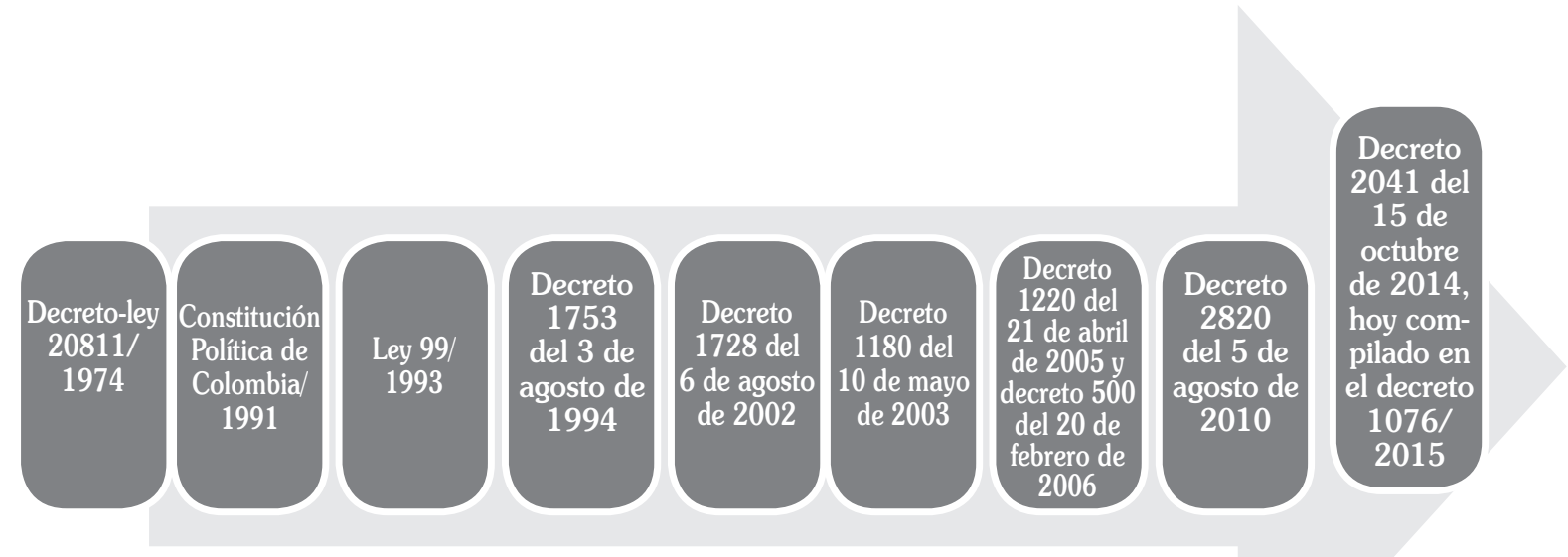

Gráfica 2. La transición desde el derecho ambiental

Fuente: elaboración propia.

Se aclara que las gráficas 1 y 2 son una mera enunciación de las normas que serán estudiadas a con-

tinuación. Veamos:

\section{Ley $20 / 1969$}

Reconoció la ley 20/19695 que los recursos naturales no renovables son propiedad de la nación, no obstante se respetarán y comprenderán las situaciones jurídicas, subjetivas y concretas debidamente perfeccionadas y vinculadas a yacimientos descubiertos, de que tratan los decretos 797/1971, 2310/1974 y 1994/1989; así como la ley 97/1993.

Dicha ley fue reglamentada por el decreto $1275 / 1970$ donde se señalaron los requisitos que los particulares antes del 23 de junio de 1973 debieron presentar con el fin de obtener el reconocimiento de la propiedad privada sobre los recursos naturales no renovables, bien fuera sobre minas adquiridas por adjudicación, redención a perpetuidad, accesión, merced, remate, prescripción o por cualquiera otra causa, título o modo, prerrogativas, privilegios, derechos sobre

Artículo 1. "Todas las minas pertenecen a la nación, sin perjuicio de los derechos constituidos a favor de terceros. Esta excepción, a partir de la vigencia de la presente ley, solo comprenderá las situaciones jurídicas, subjetivas y concretas debidamente perfeccionadas y vinculadas a yacimientos descubiertos [...]". las minas o sobre el subsuelo ${ }^{6}$. En caso de que dichos requisitos se cumplieran, en su momento el Ministerio de Minas y Energía (MME) debió reconocer la "propiedad sobre la mina" mediante acto administrativo.

Así se reconoció en general la propiedad estatal de los recursos naturales no renovables, exceptuando el caso en donde los particulares por resolución motivada del MME, fueran propietarios de la mina. Ahora bien, la excepción mencionada contaba con un requisito de temporalidad (art. 29, ley 20/1959), el cual estableció que ese reconocimiento de propiedad sobre la mina se consideraría extinguido si los interesados suspendieran la exploración o explotación por más de doce meses continuos, sin causa justificada que pudiera llegar a constituir caso fortuito o fuerza mayor. La demostración de la causa debe presentarla el interesado a requerimiento de la autoridad minera, en cualquier tiempo y en el plazo que esta le señale; lo cual deberá ser declarado por el $\mathrm{MME}^{7}$.

6 Véase sobre este particular el concepto 201006079103-11-2011 del MME.

7 Así lo reconoció el Consejo de Estado en sentencia de 29 de agosto de 2014: "Ahora, en vigencia de la Carta de 1886, y con el objeto de ajustar la legislación a los mandatos constitucionales, fue expedida la ley 20 de 
Tabla 1. Escenarios de transición ley 20/1959

\begin{tabular}{ll}
\hline \multicolumn{2}{c}{ Escenarios } \\
\hline $\begin{array}{c}\text { Registro de propiedad } \\
\text { privada }\end{array}$ & $\begin{array}{c}\text { Estado propietario } \\
\text { del subsuelo }\end{array}$ \\
\hline $\begin{array}{l}\text { Actividades mineras que } \\
\text { cuentan con propiedad pri- }\end{array}$ & $\begin{array}{c}\text { Actividades mineras ini- } \\
\text { ciadas con posterioridad }\end{array}$ \\
vada sobre los recursos na- & a la ley 20/1969 en don- \\
turales no renovables, inicia- & de el Estado es el pro- \\
das antes de la vigencia de la & pietario de los recursos \\
ley 20/1969. Dando asílugar & naturales no renovables \\
a los llamados registros de & \\
propiedad privada (RPP) & \\
\hline
\end{tabular}

Fuente: elaboración propia.

\section{En vigencia del decreto ley 2811/1974}

Con la entrada en vigencia del decreto ley 2811/1974 se consagró en Colombia la exigencia de autorizaciones ambientales para el uso de los recursos renovables ${ }^{8}$, razón por la cual es dable aseverar que en derecho ambiental se deben tener en cuenta tres momentos en el desarrollo histórico de las normas ambientales en torno a la actividad minera.

Tabla 2. Escenarios de transición ambiental iniciales

\begin{tabular}{lll}
\hline \multicolumn{3}{c}{ Escenarios } \\
\hline Con el decreto & Con la ley 99/ & Con los decretos \\
ley 2811/1974 & 1993 se exigió & $1220 / 2005$ y 500/ \\
se exigió que el & a toda actividad & 2006 se reclamó a \\
uso de recursos & minera la obten- & todo proyecto mi- \\
naturales reno- & ción de licencia & nero que estuviese \\
vables se reali- & ambiental respe- & en regímenes de \\
zara a través de & tando regímenes & transición (sin li- \\
autorizaciones & jurídicos anterio- cencia ambiental) \\
ambientales & res & la presentación de \\
& & un plan de mane- \\
& & jo ambiental
\end{tabular}

Fuente: elaboración propia.

1969 que ratificó el dominio estatal sobre todas las minas y yacimientos de hidrocarburos, sin perjuicio, como señaló su artículo $1^{\circ}$ en consonancia con el artículo 13, de los derechos constituidos a favor de terceros [...]".

8 Claro está que ya existía en nuestro país la figura de autorización para el desarrollo de algunas obras o actividades.
El Código Nacional de los Recursos Naturales Renovables y de Protección al Medio Ambiente decretó que para las diferentes formas de uso, utilización o aprovechamiento de los elementos del ambiente por parte de los particulares, se debería obtener los permisos, concesiones, asociaciones y autorizaciones allí contenidas. A manera de ejemplo, se puede evidenciar cómo el uso minero que se le da a las aguas requiere concesión, afirmando con esto que todo uso de los recursos naturales en actividades como la minera, debe estar precedido de la consecución de las citadas autorizaciones ${ }^{9}$ por cada uno de los recursos naturales renovables que fuesen utilizados, aprovechados o impactados. Esta situación cobijó también a los registros de propiedad privada de que tratan los decretos 797/1971, 2310/1974 y 1994/1989; así como la ley $97 / 1993$.

Tabla 3. Transición con el Código de Recursos Naturales Renovables y de Protección al Medio Ambiente

\section{Escenario}

Desde el 18 de diciembre de 1974 se requiere para el uso y aprovechamiento de los recursos naturales renovables, autorización, concesión, permiso o asociación. Por ende toda actividad minera existente y nueva debe obtenerlos

Fuente: elaboración propia.

\section{Con el decreto $2655 / 1988^{10}$}

El antiguo Código de Minas tenía como objetivo fomentar la exploración del territorio nacional y de los espacios marítimos jurisdiccionales, en orden a establecer la existencia de minerales; a facilitar su racional explotación; a que con ellos se atendiera las necesidades de la demanda; a crear oportunidades de empleo en las actividades mineras; a estimular la inversión en esta industria

$9 \quad$ Autorizaciones que en su momento estuvieron a cargo del Instituto Nacional de Recursos Naturales (Inderena).

10 Publicado en el 38 626, del 23 de diciembre de 1988. Derogado expresamente por el artículo 361 de la ley $685 / 2001$. 
y a promover el desarrollo de las regiones donde se adelantara.

El artículo 6 de la norma referida, contempló que los derechos de los particulares sobre el suelo, el subsuelo minero o sobre las minas, a título de adjudicación, redención a perpetuidad, accesión a la propiedad superficiaria, merced, remate, prescripción o por cualquier otra causa semejante, se extinguieron en favor de la nación si se cumplieron las condiciones y plazos de vencimiento determinados en los artículos 3, 4 y 5 de la ley 20/1969. Es decir:

1. Si al vencimiento de los tres años siguientes a la fecha de la sanción de esta ley, los titulares del derecho no iniciaron la explotación económica de las minas respectivas.

2. Si la explotación, una vez iniciada, se suspendió por más de un año.

En consecuencia, las disposiciones que fijó este Código en ningún momento tenían como finalidad revivir, ampliar o restituir dichas condiciones y plazos, ni convalidar en ningún caso, aquellos derechos sobre el suelo o el subsuelo que en virtud de las consideraciones anteriores hayan extinguido. Aclarando que los derechos de los particulares sobre las minas mencionadas que hubieren conservado su validez por iniciar y mantener la explotación económica, se extinguen igualmente en favor de la nación si suspenden dicha explotación sin causa justificada, tal como se previó en el literal b) de dicho artículo.

Por esta razón, si tales derechos se extinguieron en favor de la nación, para la exploración y explotación de los recursos naturales no renovables se debieron obtener los mecanismos administrativos para la actividad minera (que veremos enseguida). Caso contrario, continuará la propiedad sobre la mina.

Además de lo precedente, la ley en comento precisó que los títulos mineros otorgados para ser perfeccionados deben estar inscritos en un registro minero ${ }^{11}$, mediante acto administrativo a través del cual se concede el derecho a explorar y explotar el suelo y el subsuelo mineros de propiedad nacional. Es decir, que según lo dispuesto en los artículos 62 y 80 de dicha norma, el registro minero se constituye en requisito para la ejecución de los derechos allí contenidos ${ }^{12}$.

Los títulos mineros se pueden clasificar en licencias de exploración, licencias de explotación, aportes y contratos de concesión (arts. 16 y 17 decreto 2655/1988), dándoles a dichas figuras tiempos específicos de duración, así:

1. Para licencias de exploración: un año para la licencia cuya área original sea hasta de cien hectáreas, prorrogables hasta por uno más. Dos años para la que tenga un área original de más de cien hectáreas sin pasar de mil hectáreas, prorrogables hasta por un año más. De cinco años para aquella cuya área original exceda las mil hectáreas.

2. Para licencia de explotación: diez años que se contarán desde su inscripción en el registro como título de explotación (art. 46).

3. Para el contrato de concesión: treinta años contados a partir de su inscripción en el registro minero.

Además, en el antiguo Código de Minas hay disposiciones que contemplan diversas medidas para la protección del ambiente y sus componentes. A modo de ejemplo, el artículo 38 expresa que junto con el informe final de exploración y el programa de trabajos e inversiones, el interesado presentará la declaración del impacto ambiental que el proyecto minero pueda causar. Igualmente el artículo 88 contempló que en los contratos de

1 Lo cual se encuentra reglado en el decreto 2655/1988.

12 En un mismo sentido se indicó (último inciso del artículo 17) que los solicitantes de licencias, concesiones y aportes, mientras su título no sea inscrito en el registro minero, no podrán alegar ninguna situación subjetiva y concreta, oponible a la administración, ni frente a nuevas disposiciones legales que modifiquen o eliminen los sistemas de exploración y explotación mineras. 
gran minería de las entidades descentralizadas se acordaría la obligación de evaluar el impacto ambiental de las obras y trabajos y se adoptarían los correctivos necesarios para subsanarlo o mitigarlo.

El artículo 250 contempló que con base en el Informe final de exploración y el programa de trabajo e inversiones, el MME determinaría si es menester la presentación de un estudio de impacto ambiental y un plan de manejo de los recursos naturales no renovables y del medioambiente, además de la declaración de impacto ambiental.

El artículo 168 declara que sin perjuicio de los derechos que otorga la licencia ambiental de que trata el artículo 246 para la construcción, uso y mantenimiento de las obras e instalaciones necesarias para el goce de las servidumbres, será preciso obtener los permisos y concesiones que las leyes prescriban según la naturaleza y ubicación de la construcción o de su uso; de igual manera el artículo 251 expresa que además de las funciones que corresponden al MME de conformidad con lo establecido en este código, conocerá de todos los asuntos administrativos que tengan relación directa y principal con la industria minera en todas sus ramas, en cuanto no se asignen por la ley a otra autoridad.

Argumento adicional sobre este aspecto contiene el artículo 170 del decreto 2655/1988, según el cual no habrá servidumbre para tomar maderas $y$ otras especies vegetales que existan en terrenos baldíos o de propiedad particular. El minero deberá obtener permiso de la autoridad a cuyo cargo esté la conservación de dichos recursos, que será tramitado y resuelto de conformidad con las disposiciones legales sobre la materia.

Conforme con las disposiciones normativas expuestas, se puede afirmar que a pesar de que el título minero llevaba implícita la licencia ambiental, su titular debía obtener los permisos, autorizaciones, concesiones o asociaciones para el uso, aprovechamiento y utilización de los recursos naturales ante el Inderena; dichas obligaciones de tipo ambiental no reemplazaban, ni anulaban las normas del decreto ley 2811/1974; teniendo en cuenta que son cuerpos normativos diferentes (ambiental y minero) pero complementarios.

Cabe aclarar que según lo dispuesto en el artículo 246 del decreto ley en comento, el título minero al llevar implícita la licencia ambiental, contiene igualmente la autorización para utilizar en los trabajos y obras de minería, los recursos naturales renovables y del medioambiente, en la medida en que sean imprescindibles para dicha industria, con la obligación correlativa de conservarlos o restaurarlos si ello es factible, técnica y económicamente. Esta situación sin duda alguna implica que la vigencia de la licencia ambiental se limita a la vigencia del respectivo título minero con el lleno de los requisitos legales.

De lo anterior se deduce que para que el particular pudiese ejecutar su proyecto minero debía por un lado obtener el título minero, que incluía algunas medidas ambientales, y por otro, adquirir los permisos, concesiones, asociaciones y autorizaciones a los cuales hace referencia el Código Nacional de los Recursos Naturales Renovables y de Protección al Medio Ambiente.

Esta argumentación encuentra sustento en la sentencia 52/1989 de la Corte Suprema de Justicia al estudiar una acción pública de inconstitucionalidad interpuesta contra el numeral 16 del artículo 1 de la ley 57/1987 y los artículos 246-250 y 255 del decreto 2655/1988, por el cargo consistente en que los artículos acusados contenidos en el decreto 2655/1988, modifican disposiciones del Código Nacional de los Recursos Naturales Renovables y de Protección al Medio Ambiente (decreto ley 2811/1974), así como las competencias del Inderena, previstas en aquel y en el decreto ley 2420/1968; por ello, además estima que las disposiciones demandadas en cuanto le atribuyen al MME funciones propias del Inderena referidas a los recursos naturales renovables, crean una dicotomía de competencias que contraría las precitadas normatividades. Se llega a las siguientes conclusiones:

1. No debe entenderse que el MME suplante a los demás organismos encargados de la 
preservación del medioambiente y de la guarda de los recursos naturales renovables, como el Inderena; su competencia se circunscribe a vigilar esos aspectos en cuanto incidan en ellos las explotaciones mineras, que son de su jurisdicción. Tanto es ello así, que el artículo 249 exige que el Ministerio, en la expedición de normas, instrucciones y órdenes tendientes a mitigar los daños que la actividad minera pueda causar a los recursos naturales renovables y del medioambiente, obrará en permanente consulta y coordinación con las autoridades que por competencia general o por delegación, tienen a su cargo la administración y preservación de dichos recursos.

2. Plantea la Corte que lo normado en los artículos relativos a la exigencia del título minero para que, en virtud de la licencia ambiental que lleva implícita, su beneficiario pueda utilizar los recursos naturales renovables y del medioambiente en actividades mineras en tanto que sean imprescindibles para dicha industria, coincide plenamente con lo dispuesto en el libro 24, parte $1^{a}$, título $V$ del Código Nacional de los Recursos Naturales Renovables y de Protección al Medio Ambiente, cuyas disposiciones regulan de manera general los distintos modos y condiciones en que puede adquirirse por los particulares el derecho de usar los recursos naturales de dominio público, según lo estipula su artículo 50. Por su parte, el artículo 305 del Código Nacional de los Recursos Naturales Renovables y de Protección al Medio Ambiente y el artículo 253 del decreto 1541/1978, reglamentario del primero, establecen que corresponde al Inderena velar por el cumplimiento de las disposiciones del Código Nacional de los Recursos Naturales Renovables y de Protección al Medio Ambiente y de las demás normas legales sobra la materia, así como impartir las órdenes necesarias para la vigilancia y defensa de los recursos naturales renovables y del ambiente.

La Corte advierte que no se trata de competencias excluyentes sino confluyentes que si bien aluden a un área común de influencia, no se oponen sino que, por el contrario se complementan, ya que cada entidad las cumple en la esfera que le es propia y dentro de las mismas disposiciones que el actor señala como modificadas, se prevé una labor coordinada entre ellas, en particular en el propio artículo 248 , según ya se indicó.

3. Menciona la Corte que como también el artículo 249 acusado reitera la existencia de competencias concurrentes en este campo a cargo de diversas autoridades cuando para efectos de expedir las normas, instrucciones y órdenes, tendientes a evitar o mitigar los daños que la actividad minera pueda causar a los recursos naturales renovables y del medioambiente, así como de las que aseguren su conservación y restauración, por ello impone al MME el deber de obrar en permanente consulta y coordinación con las autoridades que por competencia general o por delegación, tienen a su cargo la administración y preservación de dichos recursos, una de las cuales es precisamente el Inderena.

En igual sentido, la Oficina Asesora Jurídica de la Agencia Nacional de Minería (radicado 20131200258931 del 1 de octubre de 2013) en la respuesta a la consulta de si el titular de una licencia de explotación que no tiene un instrumento ambiental puede seguir explotando minerales; expresó que si bien la licencia ambiental se entiende incorporada a las licencias de explotación otorgadas en el decreto 2655/1988, las cuales en principio se encuentran en vigencia, esto no exime que la autoridad ambiental, en desarrollo del artículo 168 del mismo decreto, pueda exigir permisos o licencias adicionales cuando considere que se está afectando el medioambiente y que estén establecidas en la normatividad ambiental. En consecuencia, caso a caso se debe determinar si fueron cumplidas las exigencias y condiciones mineras y ambientales.

Se reitera y concluye que si bien el título minero contenía algunas medidas e instrumentos para la 
protección de los recursos naturales, también se debían obtener para el desarrollo de la actividad minera, los permisos, concesiones, asociaciones $y$ autorizaciones para el uso y aprovechamiento de los recursos naturales renovables ante el Inderena.

Tabla 4. Escenarios antes de la Constitución de 1991

\begin{tabular}{ll}
\hline \multicolumn{2}{c}{ Escenarios } \\
\hline $\begin{array}{l}\text { RPP }+ \text { autorizaciones am- } \\
\text { bientales }\end{array}$ & $\begin{array}{l}\text { Títulos mineros }+ \text { autori- } \\
\text { zaciones ambientales }\end{array}$ \\
\hline
\end{tabular}

Fuente: elaboración propia.

\section{La Constitución Política de Colombia de 1991}

La forma organizativa de Estado social de derecho acogida en Colombia a partir de la Constitución de 1991, implicó un cambio trascendental en el concepto del papel del Estado contemporáneo. El tránsito del Estado liberal de derecho fundado, al Estado social de derecho (artículo 1 superior), ha conllevado la asunción de una función activa y protagónica del Estado actual como "promotor de toda la dinámica social".

Además, el cumplimiento de unos fines esenciales y sociales del Estado, como la efectividad de los principios, derechos y deberes consagrados en la Constitución (preámbulo y artículos 2 y 365), entre otros factores, ha ocasionado un incremento considerable de las funciones de la administración, que a la vez ha conducido a la ampliación de las prerrogativas permisivas, regulativas, sancionatorias y planificadoras reconocidas en los diferentes órganos del Estado sin importar la separación de sus funciones, pues todas colaboran armónicamente en la realización de sus fines (artículo 113 superior).

Nuestra Carta Magna contiene una serie de artículos que imprimen en todas y cada una de las partes que componen la nación colombiana, ciertos deberes, obligaciones, cargas y principios, en pro de la conservación de lo que podemos llamar nuestro entorno (medioambiente/riquezas naturales).
A manera de ejemplo, de conformidad con lo dispuesto en el artículo 332 de la Constitución Política de Colombia de 1991, el Estado es propietario del subsuelo y de los recursos naturales no renovables, sin perjuicio de los derechos adquiridos y perfeccionados con arreglo a las leyes preexistentes, carta que además en su artículo 360 indicó que la ley establecerá las condiciones para la explotación de los recursos naturales no renovables.

Así las cosas, desde el punto de vista ambiental, con la expedición de la Constitución Política en 1991 se estableció una Constitución ecológica donde se configuró como obligación tanto del Estado como de los particulares, proteger las riquezas culturales y naturales de la nación; por lo cual la Corte Constitucional expresó sobre la importancia de protección del bien jurídico del medioambiente y los deberes correlativos lo siguiente:

4.3. El bien jurídico constitucional del medioambiente y los deberes correlativos. La Constitución ecológica lleva implícita el reconocimiento al medioambiente de una triple dimensión: "[por] un lado, es un principio que irradia todo el orden jurídico puesto que es obligación del Estado proteger las riquezas naturales de la nación. [Por] otro lado, aparece como el derecho de todas las personas a gozar de un ambiente sano, derecho constitucional que es exigible por diversas vías judiciales. Y, finalmente, de la Constitución ecológica derivan un conjunto de obligaciones impuestas a las autoridades y a los particulares. Es más, en varias oportunidades, este tribunal ha insistido en que la importancia del medioambiente en la Constitución es de tal magnitud que implica para el Estado "unos deberes calificados de protección" (véase para mayor información las sentencias T-411/1992, C-058/1994, C-519/1994, C-328/1995, C-495/1996, C-535/1996 y C-595/2010).

Vale la pena detenernos en el análisis de la constitucionalidad del artículo 246 del decreto 
2655/1988 que instauró en su momento que la licencia ambiental se encontraba implícita en el título minero; la demanda de inexequibilidad planteó como argumento fundamental que el Código del cual forman parte las disposiciones impugnadas no cumple ni desarrolla las normas constitucionales que protegen el medioambiente. Por el contrario, al aplicar indiscriminadamente excesivos privilegios a favor de los mineros, se le causan inmensos e irremediables perjuicios.

No obstante, la Corte Constitucional (sentencia C-216 del 9 de junio de 1993) estableció que en efecto, esta disposición vulnera la preceptiva constitucional, pues a su tenor, los recursos naturales, que merecen especial protección del Estado (artículos 8, 79 y 80 de la Constitución), quedan supeditados a la utilización que de ellos hagan quienes desempeñan las actividades mineras y para los fines de estas, a lo cual se añade que la obligación impuesta por la norma en el sentido de "conservarlos y restaurarlos" no tiene aplicación práctica, pues queda librada a su factibilidad técnica y económica, lo que implica la más absoluta desprotección del medioambiente y de la riqueza natural. Como puede verse, según la Corte, la disposición que se considera, se caracteriza por la amplitud y la tolerancia en favor de la actividad minera, con evidente sacrificio del necesario cuidado del ambiente y los recursos naturales renovables, es abiertamente incompatible con tan apremiantes y concluyentes prescripciones constitucionales. En consecuencia, fue inexequible.

Como resulta de lo expuesto, la inconstitucionalidad de esta norma proviene de su oposición material con el ordenamiento fundamental vigente al pronunciar esta sentencia. Así las cosas, la Corte promulgó que al ser el ambiente un bien jurídicamente tutelable, la disposición examinada no atendía lo establecido en la carta y por ende debe expulsarse del ordenamiento jurídico.

A partir del 9 de junio de 1993 (fecha de la sentencia C-216) la licencia ambiental como instrumento de manejo y control dejó de estar implícita en el título minero. Por tal razón, el MME (concepto/radicado 2008012142/2008) ha dicho que hasta antes del 9 de junio de 1993, fecha en que se declaró inexequible el artículo $246 \mathrm{del}$ decreto $2655 / 1988$, el título minero, inscrito y en ejecución, llevaba implícita la correspondiente licencia ambiental.

Por ende, para la ejecución de la actividad minera se requería el título minero y las autorizaciones ambientales, teniendo en cuenta que se trata de competencias diferenciables (minera y ambiental) que son concurrentes en una sola actividad. Dejando sin embargo a salvo las situaciones jurídicas consolidadas antes del 9 de junio de 1993.

\section{En vigencia de la ley 99/1993}

En materia de autorizaciones ambientales para las actividades de explotación minera, la expedición de la ley 99/1993 marcó un cambio en el modo en que dichas actividades eran avaladas desde el punto de vista ambiental. Ello por cuanto de forma taxativa se indicó que la ejecución de proyectos de actividades de explotación minera debía someterse independientemente de las autorizaciones mineras, a un proceso de evaluación ambiental por parte de las autoridades ambientales designadas para tal fin, teniendo como herramienta el estudio de impacto ambiental con el propósito de obtener, de manera previa a la puesta en marcha del proyecto, la correspondiente licencia ambiental.

A partir de este momento el otorgamiento de nuevos títulos mineros exigía para su efecto la obtención de la respectiva licencia ambiental. Por tal razón los decretos 501/1996 y 1481/1996 contemplaron como requisito para la inscripción en el registro minero nacional, la presentación de la correspondiente licencia ambiental entregada por las autoridades del Sistema Nacional Ambiental (Sina).

No obstante, el artículo 117 de la ley 99/1993 señaló el régimen de transición, determinando que los permisos y licencias concedidos antes de su promulgación continuarán vigentes por el 
tiempo de su expedición y que las actuaciones administrativas iniciadas seguirán su trámite ante las autoridades que asuman su competencia en el estado en que se encuentren. Con base en lo analizado y lo dispuesto por la ley 99/1993 tenemos que:

1. Las actividades mineras amparadas en títulos otorgados en vigencia del decreto 2655/1988, que hubiesen obtenido los permisos, concesiones, autorizaciones o asociaciones, necesarios para el uso de los recursos naturales renovables; o estos estuviesen en trámite, pudieron continuar por el tiempo de su expedición y se entienden amparadas en este régimen de transición. Esta situación les permitiría proseguir durante la vigencia del título minero.

En todo caso, una vez el término inicial de dichos permisos, concesiones, autorizaciones o asociaciones llegase a su vencimiento, pudo prorrogarse como requisito válido para avalar la actividad minera, por cuanto la prórroga responde a la posibilidad jurídica de prolongar o extender en el tiempo las condiciones, consecuencias y efectos en principio establecidos (Gómez, Rodríguez y Monroy, 2012).

2. Aquellas personas que al momento en el cual la ley 99/1993 entró en vigencia se encontraran adelantando los trámites para la obtención de licencias de exploración, licencias de explotación, aportes y contratos de concesión en vigencia del decreto 2655/1988 debieron obtener la respectiva licencia ambiental antes de comenzar la actividad de explotación ante la autoridad ambiental competente.

Lo anterior teniendo en cuenta que el régimen de transición señaló de manera expresa la irretroactividad de la ley 99/1993, frente a las situaciones jurídicas consolidadas, pero su aplicación retrospectiva frente a las meras expectativas que se hallaran en trámite.
A continuación entraremos a revisar los desarrollos reglamentarios de la transición prevista en la ley 99/1993, a través de los decretos que reglamentaron el título VIII sobre licencias ambientales.

Tabla 5. La transición en la ley 99/1993

\begin{tabular}{ll}
\hline \multicolumn{2}{c}{ Escenarios } \\
\hline $\begin{array}{l}\text { RPP o título minero (antes } \\
\text { de la ley 99/1993) + auto- } \\
\text { rizaciones ambientales (con poste- } \\
\text { rioridad a la expedición de } \\
\text { la ley 99/1993) + licencia } \\
\text { ambiental }\end{array}$ \\
\hline
\end{tabular}

Fuente: elaboración propia.

\section{En vigencia del decreto 1753/1994}

El primer decreto reglamentario del título VIII de la ley 99/1993 fue el decreto 1753/1994, expedido por el Gobierno nacional con base en las facultades constitucionales consagradas en el numeral 11 del artículo 189 de la Constitución Política y en el artículo 53 de la ley 99/1993, en el que se determinó a través de sus artículos $7^{13}$ y $8^{14}$ que las actividades mineras debían obtener para la ejecución de actividades de exploración y explotación la correspondiente licencia ambiental.

Así lo contemplaron el numeral 2 del artículo 7 y el numeral 1 del artículo 8: ejecuciones de proyectos de gran minería, entendiendo estos como la exploración, montaje, producción, beneficio, almacenamiento, acopio, transporte, fundición, procesamiento y transformación de minerales, de conformidad con las definiciones y la clasificación de la gran minería contenidas en el Código de Minas y actividades de exploración, explotación, beneficio, transporte y depósito de los recursos naturales no renovables, realizadas en desarrollo de la mediana y pequeña minería.

\footnotetext{
13 "Competencia del Ministerio de Medio Ambiente [...]". 14 "Competencia de las Corporaciones Autónomas Regionales [...]".
} 
En este sentido toda actividad nueva (para la época) de exploración o explotación de minerales estaba sujeta a la obtención de la correspondiente licencia ambiental. Adicionalmente, el precitado decreto indicó en su artículo 38 (régimen de transición), entre otras cosas, que: los proyectos, obras o actividades, que según las normas vigentes antes de la expedición del decreto, consiguieron los permisos, concesiones, licencias y autorizaciones de carácter ambiental que se requerían, podrán continuar, pero la autoridad ambiental competente podrá exigirles, mediante providencia motivada, la presentación de planes de manejo, recuperación o restauración ambiental (PMRRA).

Con base en lo anterior, las autoridades ambientales estaban facultadas para exigir la presentación de PMRRA a los proyectos, obras o actividades mineras listadas en los artículos 7 y 8 , que tuviesen título minero, así como los permisos, concesiones, autorizaciones o asociaciones ambientales para el uso de los recursos naturales renovables que en su momento se requerían. De ello podemos definir los siguientes escenarios del régimen de transición del decreto:

1. En caso de existir actividades mineras amparadas en títulos mineros, que hubiesen obtenido los permisos, concesiones, autorizaciones o asociaciones ambientales que en su momento se requerían y estuviesen vigentes; y la autoridad ambiental no hizo uso de la facultad de exigir la presentación del PMRRA, pudieron continuar sus actividades.

2. En caso de existir actividades mineras amparadas en títulos mineros, que hubiesen obtenido los permisos, concesiones, autorizaciones $\mathrm{o}$ asociaciones ambientales que en su momento se requerían y estuviesen vigentes; y la autoridad ambiental hiciera uso de la facultad de exigir la presentación del PMRRA:

- Pudieron continuar, siempre y cuando hubieran presentado el PMRRA.
- En caso de no presentarlo, no pudieron proseguir con la actividad, sin perjuicio de las acciones preventivas y sancionatorias administrativas ambientales a que hubiese lugar, de conformidad con la normatividad vigente en la época.

Nótese cómo el requisito no implicaba una condición de aprobación, sino simplemente de presentación del mencionado plan, por lo cual mal se haría en interpretar la norma y solicitar en estos casos una aprobación que no forma parte del cumplimiento del requisito.

3. Actividades mineras que se encuentran en proceso de obtención del respectivo título minero, pudieron continuar dicho trámite ante la autoridad minera competente, sin embargo debieron realizar los procedimientos necesarios para la obtención de la licencia ambiental.

Respecto del numeral 3 objeto de estudio observa el Consejo de Estado (sentencia del 6 de febrero de 2003) que la única actividad que con anterioridad a la expedición de la ley 99/1993 se había iniciado era la de exploración, ya que el proyecto de explotación del yacimiento ni siquiera había alcanzado la respectiva licencia, como quiera que apenas le fue concedida el 10 de febrero de 1995; es decir, después de algo más de un año de promulgada dicha ley, que lo fue el 22 de diciembre de 1993, lo cual no significaba la iniciación de ese proyecto, toda vez que ello quedó condicionado a la obtención de las licencias ambientales correspondientes por disposición del mismo acto que le otorgaba la licencia de explotación, lo que a su vez concuerda con el hecho de que esta le fue dada en vigencia de la ley 99/1993.

Dada la similitud entre las siguientes normas no serán expuestas en cuadro de resumen, hasta el próximo escenario hito (decretos 1220/2005 y $500 / 2006)$. 
Tabla 6. La transición del decreto 1753

\begin{tabular}{lll}
\hline \multicolumn{3}{c}{ Escenarios } \\
\hline Títulos mineros & Títulos mineros & Títulos mineros \\
existentes + auto- & existentes + auto- & con autorizacio- \\
rizaciones ambien- & rizaciones ambien- & nes ambienta- \\
tales sin requeri- & tales con requeri- & les en trámite, \\
miento de la au- & miento de la au- & debieron obte- \\
toridad ambien- & toridad ambiental ner la licencia \\
tal & con presentación ambiental \\
& de los planes & \\
\hline
\end{tabular}

Fuente: elaboración propia.

\section{En vigencia de la ley $685 / 2001$}

La ley 685/2001 derogó el decreto 2655/1988, en su artículo 14 indicó que únicamente se podrá constituir, declarar y probar el derecho a explorar y explotar minas de propiedad estatal, mediante el contrato de concesión minera, debidamente otorgado e inscrito en el Registro Minero Nacional, dejando a salvo los derechos provenientes de las licencias de exploración, permisos o licencias de explotación, contratos de explotación y contratos celebrados sobre áreas de aporte, vigentes al entrar a regir dicho estatuto. Es importante advertir que a partir de la expedición de esta norma la actividad de exploración minera dejó de requerir licencia ambiental, siendo reemplazada por la presentación de las guías minero-ambientales ${ }^{15}$. Con ello entonces encontramos lo siguiente:

1. Tal y como ocurrió con el primer escenario del decreto 1753/1994, en caso de existir actividades mineras amparadas en títulos mineros, que hubiesen obtenido los permisos, concesiones, autorizaciones o asociaciones ambientales que en su momento se requerían y estuviesen vigentes; y la autoridad ambiental no hizo uso de la facultad de exigir la presentación del PMRRA, pudieron continuar sus actividades.

15 Es de anotar que de conformidad con los decretos posteriores se exigió la obtención de la licencia ambiental para la etapa de exploración cuando sea necesaria la construcción de vías.
2. En caso de existir actividades mineras amparadas en títulos mineros, que hubiesen obtenido los permisos, concesiones, autorizaciones o asociaciones ambientales que en su momento se requerían y estuviesen vigentes; y la autoridad ambiental hiciera uso de la facultad de exigir la presentación del PMRRA:

Pudieron continuar, siempre y cuando hubieran presentado el PMRRA.

Tal y como ocurrió con el primer escenario del decreto 1753/1994, en caso de no presentarlo, no pudieron continuar con la actividad, sin perjuicio de las acciones preventivas $y$ sancionatorias administrativas ambientales a que hubiese lugar, de acuerdo con la normatividad vigente en la época.

3. Las actividades mineras de que tratan los literales a) y b) antes descritos, que a la entrada de la ley 685/2001 decidieron realizar cesión de áreas, integración de áreas o concesiones concurrentes, teniendo en cuenta que dichas figuras comprenden un nuevo contrato que debe sujetarse a las reglas jurídicas existentes al momento de su suscripción, debieron obtener licencia ambiental según el marco jurídico establecido en la ley 99/1993 y el decreto 1753/1994. Sin que sobre el particular se encuentre jurisprudencia directamente relacionada que nos dé luces sobre la interpretación de las situaciones expuestas.

\section{En vigencia del decreto 1728/2002}

Con la expedición del decreto 1728/2002, en el que nuevamente se indicó que los proyectos de explotación minera requerían para su ejecución de la obtención de la correspondiente licencia ambiental (arts. 8 y 9), se definió respecto del régimen de transición que los proyectos, obras o actividades que conforme con las normas vigentes antes del 3 de agosto de 1994 se encontraran en ejecución, podrán continuar su desarrollo y operación, pero la autoridad ambiental competente, podrá exigirles en función del seguimiento 
ambiental y mediante acto administrativo motivado, las medidas ambientales adicionales que se consideren necesarias o el ajuste de las que se estén implementando. También adujo que no obstante lo anterior, el proyecto deberá contar con todos los permisos, concesiones o autorizaciones de carácter ambiental requeridos para el aprovechamiento y afectación de los recursos naturales renovables por parte del proyecto, obra o actividad (art. 34).

Nótese cómo el decreto 1728/2002 facultó nuevamente a las autoridades ambientales para exigir mediante acto administrativo motivado y en el marco de la función de seguimiento y control, medidas ambientales adicionales ${ }^{16}$ que consideraran necesarias o el ajuste de las que se estuviesen implementando, a los proyectos, obras o actividades que se hallaban operando antes del 3 de agosto de 1994, a efectos de que dichas medidas fungiesen como instrumento de control, para las licencias de explotación en operación, que hubiesen obtenido las autorizaciones, permisos y concesiones de la época; generando así los mismos escenarios de la norma precedente. Sin que sobre el particular se encuentre jurisprudencia directamente vinculada que nos dé luces sobre la interpretación de las situaciones ya expuestas.

\section{En vigencia del decreto 1180/2003}

Mediante la expedición del decreto 1180/2003 se derogaría el decreto 1728/2002 en el que como ya era común, las actividades de explotación minera estarían sujetas a licenciamiento ambiental. La norma en cita estableció en el artículo 28 que:

1. Los proyectos, obras o actividades, que de acuerdo con las normas vigentes antes de la expedición del decreto, obtuvieron los permisos, concesiones, licencias y autoriza-

16 Obsérvese cómo este decreto al igual que el anterior, contempla instrumentos de manejo y control ambiental del plan de manejo ambiental y el plan de manejo, recuperación y restauración ambiental, como medidas adicionales ambientales. ciones de carácter ambiental que se requerían, continuarán sus actividades sujetos a los términos, condiciones y obligaciones señalados en los actos administrativos asî expedidos.

La norma establece que aquellas actividades mineras que hubiesen obtenido las diversas autorizaciones que en su momento existieran en el ordenamiento jurídico (antes del 10 de mayo de 2003), pudieron continuar con dichas reglas. Así las cosas encontramos que ello comprende:

- Las actividades cobijadas por los diferentes regímenes de transición vistos.

- Aquellas actividades amparadas por títulos mineros otorgados en vigencia de la ley 685/2001 que cuenten con licencia ambiental de acuerdo con la ley 99/1993 y sus decretos reglamentarios.

En otras palabras, según aparte transcrito se entenderán avaladas por tener los permisos, concesiones, licencias y autorizaciones de carácter ambiental que se requerían; tanto aquellas actividades mineras inmersas en los regímenes de transición, como aquellas que poseen la respectiva licencia ambiental.

2. Los proyectos, obras o actividades que con anterioridad a la expedición del decreto iniciaron todos los trámites tendientes a obtener la correspondiente licencia ambiental o el establecimiento del plan de manejo ambiental (PMA), exigido por la normatividad en ese momento vigente, proseguirán su trámite de acuerdo con los mismos y en caso de obtenerlos podrán adelantar o seguir el proyecto, obra o actividad.

Así, los títulos mineros vigentes, que hubiesen iniciado el procedimiento para obtener los permisos, concesiones y autorizaciones ambientales que en su momento se requerían para el uso de los recursos naturales; o en los cuales la autoridad ambiental exigió la presentación de un instrumento de manejo y control o medidas 
adicionales, donde se cumplió con dicho requisito de presentación continuarán el proceso según las normas de dicha época. En caso de no obtenerlos, la autoridad ambiental debió imponer las medidas que consideró pertinentes para la restauración y recuperación de la zona impactada. Sin que sobre estos puntos se encuentren manifestaciones judiciales.

\section{En vigencia del decreto 1220/2005}

Después se derogaría el decreto 1180/2003 mediante la expedición del decreto 1220/2005, en el que se exige la licencia ambiental correspondiente para las actividades mineras (arts. $8 \mathrm{y}$ 9). Sin embargo su régimen de transición indicó que (art. 40) los proyectos a los que se refieren los artículos 8 y 9 del decreto, que hayan iniciado actividades con anterioridad a la expedición de la ley 99/1993 y no cuenten con autorización ambiental para su operación podrán continuar, para lo cual deberán presentar ante la autoridad ambiental competente un PMA. De igual forma, aquellos que estén inactivos y pretendan reanudar actividades, deberán presentar un PMA para su evaluación y establecimiento. Los interesados deberán presentar el PMA a más tardar dentro de los dos años siguientes a la publicación del decreto. Con esta norma, se crean cuatro escenarios particulares:

1. Aquellos proyectos iniciados antes de la expedición de la ley 99/1993 que no cuenten con autorización ambiental para su operación, es decir:

- Los títulos mineros obtenidos antes de la expedición de la ley 99/1993 y que contaban con los permisos, concesiones y autorizaciones para el uso de los recursos naturales renovables que en su momento se requerían, $y$ en vigencia de los decretos 1753/1994, 1728/2002 y 1180/2003 la autoridad ambiental no les exigió bien sea la presentación de un PMRRA o de medidas de manejo adicionales para su operación, debieron presentar un PMA.
- En caso de existir actividades mineras amparadas en títulos mineros obtenidos con anterioridad a la expedición de la ley 99/1993, que hubiesen obtenido los permisos, concesiones, autorizaciones o asociaciones ambientales que en su momento se requerían y estuviesen vigentes; y en vigor de los decretos $1753 / 1994,1728 / 2002$ y $1180 / 2003$ la autoridad ambiental les exigió bien sea la presentación de un PMRRA o de medidas de manejo adicionales para su operación y no lo presentaron, debieron presentar un PMA.

- Actividades mineras amparadas en títulos mineros obtenidos con anterioridad a la expedición de la ley 99/1993, que no tuviesen autorización ambiental para el uso de los recursos naturales renovables, pese a que la normatividad se lo exigía, debieron presentar un PMA.

Entonces, aquellos proyectos que deseen legalizar su situación ambiental, aunque podrán continuar, deberán presentar un PMA durante los dos años siguientes a la expedición de dicho decreto.

En caso de no presentar dicho PMA al vencimiento del término antes descrito debieron suspender actividades, sin perjuicio de las acciones administrativas sancionatorias del caso.

2. Aquellos proyectos que hubiesen suspendido actividades y se encuentren inactivos, bien hayan obtenido en su momento la autorización ambiental o no; en caso de considerar la posibilidad de reanudar deberán presentar un PMA para hacerlo. En caso de no ser aprobado o establecido, no podrán reanudar actividades.

3. Aquellos proyectos que cuenten con instrumentos de manejo y control ambiental para su operación, podrán continuar de acuerdo con las reglas con las cuales venían operando. 
4. Aquellos proyectos mineros cuyo instrumento de manejo y control para su operación se encontrase en trámite, podrán continuar; atendiendo lo dispuesto en el artículo 40 de la ley $153 / 1887^{17}$, donde se establece que los términos que hubiesen empezado a correr y las diligencias que ya estuviesen iniciadas, se regirán por la ley vigente al tiempo de su iniciación.

\section{En vigencia del decreto 500/2006}

El decreto 500/2006 modificaría el artículo 40 del decreto $1220 / 2005$, consagrando que los proyectos, obras o actividades, que de acuerdo con las normas vigentes antes de la expedición del decreto, obtuvieron los permisos, concesiones, licencias y demás autorizaciones de carácter ambiental que se requerían, continuarán sus actividades sujetos a los términos, condiciones y obligaciones señalados en los actos administrativos así expedidos.

Esto comprende aquellos proyectos iniciados antes de la expedición de la ley 99/1993 que cuenten con instrumentos de manejo y control ambiental para su operación, los cuales podrán proseguir de acuerdo con las reglas vigentes en dicha época. Los proyectos, obras o actividades que con anterioridad a la expedición del decreto 1220/2005 iniciaron todos los trámites tendientes a obtener la correspondiente licencia ambiental o el establecimiento del PMA, exigido por la normatividad en ese momento vigente, continuarán su trámite en armonía con la misma y en caso de obtenerla podrán adelantar o continuar el proyecto, obra o actividad.

Teniendo en cuenta que con lo dispuesto en el artículo 40 del decreto 1220/2005 se planteó por primera vez que el PMA podía ser considerado como instrumento de manejo y control ambiental equivalente a la licencia ambiental, ya que los decretos 1753/1994, 1180/2003 y 1728/2002 exigían figuras diferentes (PMRRA o de medidas de manejo adicionales para su operación); el numeral 2 del decreto 500/2006, es aplicable a:

17 Modificado por el artículo 624 de la ley 1564/2012.
- Los planes de manejo ambiental presentados en virtud de lo dispuesto en el artículo 40 del decreto 1220/2005.

- Todos los trámites para la obtención de una licencia ambiental.

Entonces, las actividades que se encuentren en los escenarios anteriores continuarán sus trámites con las reglas con las cuales iniciaron dicho procedimiento y en caso de obtenerlos (o ser aprobados o impuestos) podrán continuar, siempre y cuando se hubiese resuelto de manera favorable y definitiva su situación, es decir, hubiesen obtenido la licencia ambiental o les hubieran aprobado o impuesto el instrumento de manejo y control ambiental.

El numeral 3 del mencionado decreto, estableció que los proyectos, obras o actividades que hayan iniciado su operación antes de la expedición de la ley 99/1993, y que a la entrada en vigencia del decreto pretendan reanudar actividades, deberán presentar ante la autoridad ambiental competente un PMA para su respectiva evaluación y establecimiento.

$\mathrm{Al}$ igual que en la norma precedente, aquellos proyectos que hubiesen suspendido actividades y se encuentren inactivos, en caso de considerar la posibilidad de reanudar deberán presentar un PMA para hacerlo. En caso de no ser aprobado o establecido, no podrán reanudar actividades. Esto es, la mera presentación no da lugar a reanudar la actividad.

Además, los proyectos, obras y actividades que se encuentren operando a la entrada en vigencia del decreto y no cuenten con la licencia ambiental respectiva, deberán presentar un PMA ante la autoridad ambiental competente, dentro de los doce meses siguientes a la expedición del mismo, para su respectiva evaluación y establecimiento. Lo anterior sin perjuicio de la imposición de las medidas preventivas y sancionatorias a que haya lugar.

Estableciendo que aquellos proyectos mineros que consolidaron su situación jurídica con 
posterioridad a la ley 99/1993 y que, pese a que la normatividad les exigía la obtención de licencia, para la fecha de la expedición del decreto no contaban con dicho instrumento, debieron entonces presentar un PMA antes del 21 de febrero de 2007, sin perjuicio de las acciones sancionatorias correspondientes por no obtener la licencia ambiental.

Así las cosas, si dicho PMA hubiese sido presentado por quien ejecuta la actividad minera antes del 21 de febrero de 2007, deberá entenderse que el interesado está en el régimen de transición que contempla este decreto, y por ende pudo continuar, salvo que la autoridad ambiental dispusiera cosa diferente.

Nótese cómo se requiere para configuración de la transición la manifestación bien sea positiva o negativa por parte de la autoridad ambiental sobre el PMA, lo cual nos genera las siguientes posibilidades:

1. La aprobación o imposición del PMA presentado, situación con la cual se deberá entender la existencia del correspondiente instrumento de manejo y control ambiental para la actividad.

2. La negación o rechazo del PMA presentado, suceso en el que la autoridad ambiental deberá imponer las medidas para el cierre, abandono y restauración de la actividad.

3. La no presentación del PMA en la fecha antes descrita, lo cual dará lugar a estudiar la viabilidad de constituir al obligado como presunto sujeto pasivo de las acciones sancionatorias y preventivas contempladas en el régimen sancionatorio ambiental; sin perjuicio de exigir la presentación del respectivo PMA.

4. En tanto la autoridad ambiental no se pronuncie sobre la imposición o aprobación del PMA presentado, la actividad pudo continuar hasta tanto no se cuente con la decisión del caso.
Tabla 7. La transición con el decreto 500

\section{Escenarios}

Actividades mineras existen- Títulos mineros nuevos tes antes de la ley 99/1993 en + licencia ambiental regímenes de transición (sin licencia ambiental) + PMA

Fuente: elaboración propia.

\section{En vigencia del decreto 2820/2010}

Los decretos 1220/2005 y 500/2006 serían derogados por el decreto 2820/2010 que en su artículo 40 contempló dos variables de transición normativa, a saber:

1. Los proyectos, obras o actividades que iniciaron los trámites para la obtención de una licencia ambiental o el establecimiento de un PMA exigido por la normatividad en ese momento vigente, continuarán sus trámites de acuerdo con la misma y en caso de obtenerla podrán adelantar o continuar el proyecto, obra o actividad, en armonía con los términos, condiciones y obligaciones que se expidan para el efecto.

Según lo anterior, quienes solicitaron una licencia ambiental o presentaron para análisis e imposición un PMA sin que hasta el momento se tenga un pronunciamiento definitivo por parte de la administración o aquellas personas que se hallan en alguno de los procesos de los regímenes de transición vistos con anterioridad, podrán continuar siempre y cuando sean aprobados o impuestos. Caso contrario deberán suspender actividades.

2. Los proyectos, obras o actividades que de acuerdo con las normas vigentes antes de la expedición del decreto, adquirieron los permisos, concesiones, licencias y demás autorizaciones de carácter ambiental que se requerían, continuarán sus actividades sujetos a los términos, condiciones y obligaciones 
señalados en los actos administrativos así expedidos. Entre los cuales encontramos los proyectos mineros amparados en alguna autorización administrativa para su operación ambiental, tal y como lo son:

- Aquellas actividades mineras inmersas en algún régimen de transición, es decir, quienes obtuvieron en vigencia del decreto 1753/1994 el PMRRA, o en vigor de los decretos 1180/2003 y 1728/2002 las medidas de manejo adicionales; $y$ por último aquellos que en virtud de los decretos 1220/2005 y 500/2006 obtuvieron el PMA.

- Aquellas actividades que ya cuentan con licencia ambiental.

\section{En vigencia del decreto 2041/2014}

El artículo 53 del decreto 2041/2014 derogó el decreto 2820/2010, no obstante y como ha sido una constante en su artículo 52, se estableció un régimen de transición que se aplicará a los proyectos, obras o actividades que se encuentren en los siguientes casos:

1. Los proyectos, obras o actividades que iniciaron los trámites para la obtención de una licencia ambiental o el establecimiento de un PMA o modificación de los mismos, continuarán su trámite a la luz de la norma vigente en el momento de su inicio.

No obstante, los solicitantes que iniciaron los trámites para la obtención de una licencia ambiental o el establecimiento de un PMA, y cuyo proyecto, obra o actividad esté en el listado de actividades descritas en los artículos 8 y 9 de esta norma, podrán pedir a la autoridad ambiental competente la terminación del proceso, en lo que le fuera aplicable. Desde los presupuestos de esta norma tenemos que los proyectos, obras o actividades de minería que se hallen:

- En proceso para la obtención de una licencia ambiental, continuarán el mismo con ajuste a las reglas existentes en su momento de inicio, sin que puedan emprender actividades de explotación antes de su obtención.

- En proceso para la modificación de una licencia ambiental, continuarán el mismo de acuerdo con las reglas existentes en su momento de inicio de la modificación, pudiendo proseguir las actividades ya licenciadas, sin embargo absteniéndose de realizar aquellas que requieren de la modificación del instrumento ambiental, hasta tanto sean aprobadas.

- En proceso para el establecimiento, imposición o aprobación del PMRRA (decreto 1753/1994), de las medidas de manejo adicionales (decretos 1180/2003 y 1728/2002); o del PMA (decretos 1220/2005 y 500/2006), según sea el caso.

Ahora bien, aquellas actividades que dejaron de ser objeto de licencia ambiental, podrán solicitar la terminación del proceso, lo cual no es el caso de la actividad minera.

2. Los proyectos, obras o actividades, que según las normas vigentes antes de la expedición del decreto, obtuvieron los permisos, concesiones, licencias y demás autorizaciones de carácter ambiental que se requerían, continuarán sus actividades sujetos a los términos, condiciones y obligaciones señalados en los actos administrativos así expedidos.

Respetando con esta norma el escenario del literal b) del decreto 2820/2010, es decir, los proyectos mineros amparados en alguna autorización administrativa ambiental, tal y como lo son:

- Aquellas actividades mineras inmersas en algún régimen de transición, esto es, quienes obtuvieron en vigencia del decreto 1753/1994 el PMRRA, o en vigencia de los decretos $1180 / 2003$ y 1728/2002 las medidas de manejo adicionales; y por último aquellos que en virtud de los decretos 1220/2005 y 500/2006 adquirieron el PMA.

- Aquellas actividades que ya cuentan con licencia ambiental. 
Por último, es imprescindible aclarar que tal como ocurrió con todos los sectores del Estado, el pasado año 2015 se expidió el decreto único reglamentario en materia ambiental: decreto 1076/2015.

Así las cosas, el cumplimiento de la normatividad por parte de las actividades mineras, depende del momento histórico en el cual iniciaron estas y las transiciones normativas que las cobijaron. En este sentido, se invita a la comunidad estatal, empresarial y académica a discutir el tema en busca de seguridad jurídica para que de este modo se tengan reglas claras para la protección del ambiente y el crecimiento económico del país en el marco del desarrollo sostenible.

\section{Conclusiones}

El estudio de las autorizaciones administrativas que a través de la historia colombiana se han solicitado para el despliegue de la actividad minera, muestra cómo el análisis que sobre cada caso en particular realiza la autoridad ambiental es sumamente complejo, teniendo que verificar entre otros: el ordenamiento jurídico vigente al inicio de la actividad, los requisitos adicionales que nacen con la reglamentación posterior y su situación actual. Con ello, cada autoridad encontrará si el particular en efecto cumple con sus obligaciones ambientales, o si por el contrario debe ser sujeto de reproche jurídico, bien sea en sede de procesos sancionatorios $\mathrm{u}$ otras medidas pertinentes.

Además, el estudio muestra cómo cada régimen de transición creó escenarios donde el particular debió satisfacer ciertos requisitos que son y serán los exigibles en el tiempo para la actividad. Con una peculiaridad: en caso de que el particular incumpla con las obligaciones de cada régimen de transición, esto no conlleva su exclusión del mismo (y por ende hacerle exigible el ordenamiento hoy vigente); sino que lo mantiene en dicho régimen de transición, pero con la posibilidad de constituirlo como sujeto pasivo de las acciones administrativas sancionatorias del caso.
Se llama la atención sobre la complicación interpretativa que la materia en estudio ha traído. Complejidad que viene desencadenando el comportamiento diferencial entre las autoridades ambientales regionales y el diverso tratamiento a los distintos proyectos del país.

Por tal razón, es importante avanzar en el estudio de las transiciones y cambios normativos de cada una de las actividades que regula el derecho ambiental, para así lograr una actuación coherente y unificada de las entidades que componen el Sina.

\section{Referencias}

Agencia Nacional de Minería. (2013). Radicado 20131200258931. Oficina Asesora Jurídica.

Consejo de Estado, Sala de lo Contencioso Administrativo. Sección Primera. (2003). Sentencia del 6 de febrero. C. P.: Manuel Santiago Urueta Ayola.

Consejo de Estado, Sala de lo Contencioso Administrativo. Sección Tercera, Subsección B. (2014). Sentencia del 29 de agosto. Radicación 11001-03-26-0001991-07118-01(7118). C. P.: Ramiro de Jesús Pazos Guerrero.

Corte Constitucional de Colombia. (1992). Sentencia T-411. M. P.: Alejandro Martínez Caballero.

Corte Constitucional de Colombia. (1993). Sentencia C-216. M. P.: José Gregorio Hernández Galindo.

Corte Constitucional de Colombia. (1994). Sentencia C-058. M. P.: Alejandro Martínez Caballero.

Corte Constitucional de Colombia. (1994). Sentencia C-519. M. P.: Vladimiro Naranjo Mesa.

Corte Constitucional de Colombia. (1995). Sentencia C-328. M. P.: Eduardo Cifuentes Muñoz. 
Corte Constitucional de Colombia. (1996). Sentencia C-495. M. P.: Fabio Morón Díaz.

Corte Constitucional de Colombia. (1996). Sentencia C-535. M. P.: Alejandro Martínez Caballero.

Corte Constitucional de Colombia. (2001). Sentencia C-329. M. P.: Rodrigo Escobar Gil.

Corte Constitucional de Colombia. (2010). Sentencia C-595. M. P.: Jorge Iván Palacio Palacio.

Corte Suprema de Justicia. (1989). Sentencia 52 del 24 de agosto. Expediente 1933. Aprobada por acta 30. M. P.: Hernando Gómez Otálora.

Gómez, A., Rodríguez, G. A. \& Monroy, J. C. (2012). Las licencias ambientales en Colombia. Una mirada desde la participación y la responsabilidad. Bogotá: Ediciones Jurídicas Gustavo Ibáñez.

Macías, L. F. (2006). Licencias y permisos ambientales. En: B. Londoño, G. A. Rodríguez y G. Herrera (eds.). Perspectivas del derecho ambiental en Colombia (pp. 229-252). Bogotá: Universidad del Rosario.

Ministerio de Ambiente y Desarrollo Sostenible. (2014). Concepto/radicado MADS 4120E1-33037 del 25 de septiembre.

Ministerio de Minas y Energía. (2008). Concepto/ radicado 2008012142 .

Real Academia Española. (15 de febrero de 2016). Definición de "régimen" y "transición". Disponible en: http://dle.rae. es/?id=ViiZ39k

Rodríguez, G. A. (2009). La licencia ambiental, un acto administrativo especial y su proceso de flexibilización. En: M. A. Restrepo (comp.). Retos y perspectivas del derecho administrativo (pp. 222-245). Bogotá: Universidad del Rosario.

Rodríguez, G. A. (2011). Las licencias ambientales y su proceso de reglamentación en Colombia. Análisis, 1, pp. 1-16. 